\title{
Description of hitherto unknown fundatrices of Stomaphis graffii and S. longirostris (Hemiptera, Aphididae, Lachninae)
}

\author{
Łukasz Depa ${ }^{1}$, Mariusz Kanturski ${ }^{1}$ \\ 1 Zoology Department, Faculty of Biology and Environmental Protection, University of Silesia, Bankowa 9, PL 40-007 Katowice \\ Corresponding author: Lukasz Depa (lukasz.depa@us.edu.pl)
}

Received 3 February 2014

Accepted 11 March 2014

Published 30 May 2014

Academic editor:

Dominique Zimmermann

\section{Key Words}

Aphids

Lachninae

fundatrix

host specificity

\begin{abstract}
The hitherto unknown fundatrices of two large aphid species having a cryptic mode of life, Stomaphis graffii Cholodkovsky, 1894 and S. longirostris (Fabricius, 1787), are described from specimens collected in Poland. Key to identification of known fundatrices of European representatives of the genus Stomaphis is provided and the observed morphological features are discussed.
\end{abstract}

\section{Introduction}

The genus Stomaphis Walker comprises about 30 aphid species distinctive because of their large body size and very long rostrum. Such a long rostrum, much longer than the body, enables them to probe through the bark of the trees, mainly deciduous, on which they feed (Blackman and Eastop 1994). Species of the genus Stomaphis are generally monoecious (their life cycle requires only a single host plant species) with one possible exception (Takada 2008). Despite their large body size, these aphids are relatively rarely found, due to their cryptic life mode (Depa et al. 2012), and as a result little is known of the bionomy of many species. In some cases there exist only descriptions of viviparous females (Qiao and Zhang 1999). That is also why there are accounts of the first spring generation - the fundatrix - for only two Quercus-feeding species, S. quercus (L.) (Lorenz and Scheurer 1998) and S. wojciechowskii Depa (Depa and Mróz 2012). This paper aims at adding to our knowledge of the morphology of this group of aphids by providing descrip- tions of the fundatrices of two other common European representatives of the genus which feed on Aceraceae and Salicaceae, S. graffii and S. longirostris, and comparing them with the other fundatrices known in this genus.

\section{Materials and Methods}

- 15.06.2012. Piekary Śląskie, Poland, 50²4’11.85’N; $18^{\circ} 56^{\prime}$ 5.07'E. Base of trunk of Populus nigra, under the bark, associated with Lasius brunneus, leg. Ł. Depa. Stomaphis longirostris det. Ł. Depa, 4 fundatrices.

- 19.05.2012. Świerklaniec, Poland, 50²6’5.36”N; $18^{\circ} 56$ '49.84'E. Base of trunk of Acer pseudoplatanus, under the bark, associated with Lasius brunneus, leg. Ł. Depa. Stomaphis graffii det. Ł. Depa, 5 fundatrices.

Additional material studied:

- 02.06.2011, Piekary Śląskie, Poland, 50²4'11.48’N, $18^{\circ} 57^{\prime} 47.87^{\prime \prime} \mathrm{E}$, Dioblina forest, the trunk of Quercus 
robur, associated with Lasius brunneus, leg. Ł. Depa. Stomaphis wojciechowskii det. Ł. Depa, 2 fundatrices. - 10.06.2011, Bobrowniki, Poland, 50²2’38.8’N, $18^{\circ} 59^{\prime} 50.5^{\prime}$ 'E, trunk of Betula pendula, associated with Lasius fuliginosus, leg. Ł. Depa. Stomaphis quercus det. Ł. Depa, 2 fundatrices.

Measurements and photographs were made by the Nikon Eclipse E600 microscope. Microscopic slides with the studied specimens are deposited in the collection of Zoology Department of the University of Silesia, Katowice, Poland.

For comparison, basic morphometric data of $S$. acquerinoi and $S$. knechteli were obtained from Binazzi (2001), Binazzi and Blackman (2003), S. juglandis from Petrović (1998) and S. cupressi from Pintera (1965) and Mamontova (2012). Some morphometric data of apterous viviparous females were provided from Depa and Mróz (2013).

Principal Component Analysis of the key morphological (second segment of hind tarsus (HTII)/second segment of middle tarsus (MTII), number of setae on labrum, number of rhinaria on antennal segment III, number of rhinaria on antennal segment IV, sclerites on abdominal tergite VII) and ecological traits (host plant, holocycle/anholocycle) was also applied in order to determine the similarity of representatives of the $S$. longirostris - group of species and the described fundatrices. For analysis the MVSP 3.21 by Kovach Computing Services program was applied.

\section{Results}

\section{Stomaphis longirostris}

http://species-id.net/wiki/Stomaphis_longirostris Fundatrix (Fig. 1, Table 1)

Description: Body large, oval. Head distinctly sclerotised, dark. Antennae pale, with first two segments darker, densely covered with short setae (Fig.1a). Legs dark, with only middle of tibiae slightly paler. Head covered with numerous short setae. Epicranial suture well developed. Eyes small, with triommatidia not well separated. Antennae 0.13 - 0.34 times body length. Antennal segments IV and VI shorter than $\mathrm{V}$, which is thinner in the middle of its length (Fig. 1b, compare with apterous viviparous female - Fig. $3 \mathrm{ab})$. Antennal ratios: ant. segm. III/ segm. IV+V+VI 0.62 - 0.64; segm. III/ segm. IV $2.03-2.42$; segm. IV/ segm. V $0.60-0.83$; segm. V/ segm. VI $1.24-1.57$; segm. VI base/ segm. VI terminal process $4.30-6.25$. Secondary rhinaria of unequal diameter on III and IV antennal segments. Accessory rhinaria on antennal segment VI diffused on the base of segment. Terminal process subequal to the diameter of primary rhinarium, with nodose protuberances at the apex (Fig. 1c). Rostrum longer than body. Labrum covered with 1-5 setae (Fig. 1d). Apical segment of rostrum (ARS) $1.64-1.79$ times HT II and $2.46-2.95$ ant. segm. VI terminal process, with numerous accessory setae.

Prothorax dark, with spinal and marginal sclerotizations. Meso- and metathorax with marginal sclerites only.

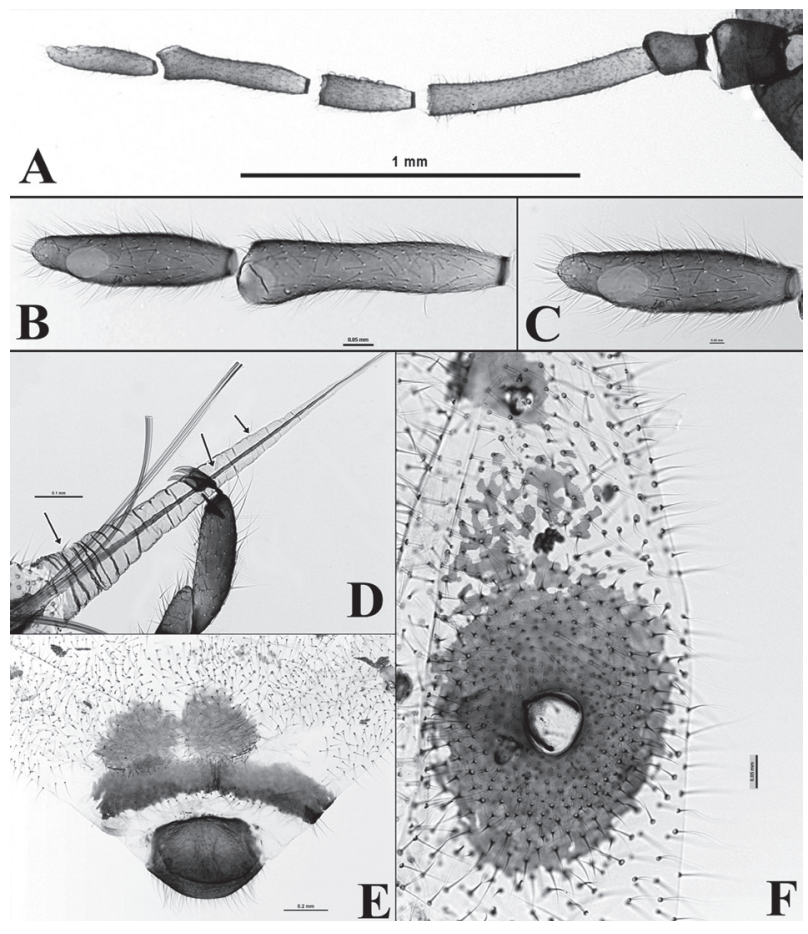

Figure 1. Stomaphis longirostris - fundatrix: (a) antenna, (b) antennal segments V and VI, (c) antennal segment VI, (d) labrum (arrows indicate setae), (e) distal part of abdomen with subgenital plate and cauda, (f) siphuncular sclerite.

Mesothoracic furca small, well separated. Metathoracic furca reduced, only in form of small, distinctly sclerotised protuberances. Legs covered by long and pointed setae, as long as the diameter of tibia in the middle. HT II 1.26 - 1.36 times second segment of middle tarsus (MT II). Ratio of ant. segm. IV to HT II $0.68-0.81$.

Abdomen membranous, covered with fine, long setae, with three rows of dark, intersegmental insertions. Spiracles on very small, pigmented sclerites. Siphuncular pores on distinct, sclerotised cones. Anterior part of the cone often extended, broken into smaller scleroites (Fig. 1f, unlike in apterous viviparous female - Fig.3d). Weak, paired spinal sclerites, often broken into many small scleroites, sometimes absent, on abdominal tergite VII. Abdominal tergite VIII distinctly and uniformly sclerotised, covered with a few rows of long setae in the posterior part of the tergite. Subgenital plate separated into two big sclerites, covered with long setae. Cauda rounded, sclerotised, covered with many long setae (Fig. 1e).

Diagnosis: From the apterous viviparous female it may be distinguished by (fundatrix vs apterous viviparous female):

- lower ratio of ant. segm. IV to ant. segm. V: $0.6-0.83$ vs $0.67-1.03$

- higher ratio of ant. segm. V to ant. segm. VI: $1.24-$ 1.57 vs $0.96-1.32$

- lower ratio of second segment of hind tarsus (HT II) to second segment of middle tarsus (MT II): $1.26-$ 1.36 vs $1.36-1.43$ 


\section{Stomaphis graffii}

http://species-id.net/wiki/Stomaphis_longirostris Fundatrix (Fig. 2, Table 1)

Description: Body large, oval. Head distinctly sclerotised, dark. Antennae pale, but with apices of segments (especially V and VI) darker, densely covered with short setae (Fig. 2a). Prothorax dark. Legs dark, with only middle of tibiae slightly paler at the ventral margin. Head covered with short setae. Epicranial suture well developed. Eyes small, with triommatidia not well separated. Antennae $0.31-0.34$ times body length. Antennal segments IV and VI shorter than ant. segm. V, which is slightly thinner in the middle of its length (Fig. 2b). Antennal ratios: ant. segm. III/ segm. IV+V+VI $0.65-0.67$; segm. III/ segm. IV 2.44 - 2.87; segm. IV/ segm. V 0.56 - 0.67; segm. V/ segm. VI 1.17 - 1.32; segm. VI base/ segm. VI terminal process $3.12-4.16$. Secondary rhinaria of unequal diameter on ant. segm. III and segm. IV. Accessory rhinaria on ant. segm. VI diffused on the base of segment. Terminal process slightly longer than the diameter of primary rhinarium, with nodose protuberances at the apex (Fig. 2c). Rostrum longer than body. Labrum covered with 6-14 setae (Fig. 2d). ARS $1.41-1.60$ times HT II and 2.14 - 2.56 ant. segm. VI terminal process, with numerous accessory setae.

Prothorax with spinal and marginal sclerotizations. Meso- and metathorax with marginal sclerites only. Mesothoracic furca small, well separated. Metathoracic furca reduced, only in form of small, distinctly sclerotised protuberances. Legs covered by long setae, as long as the

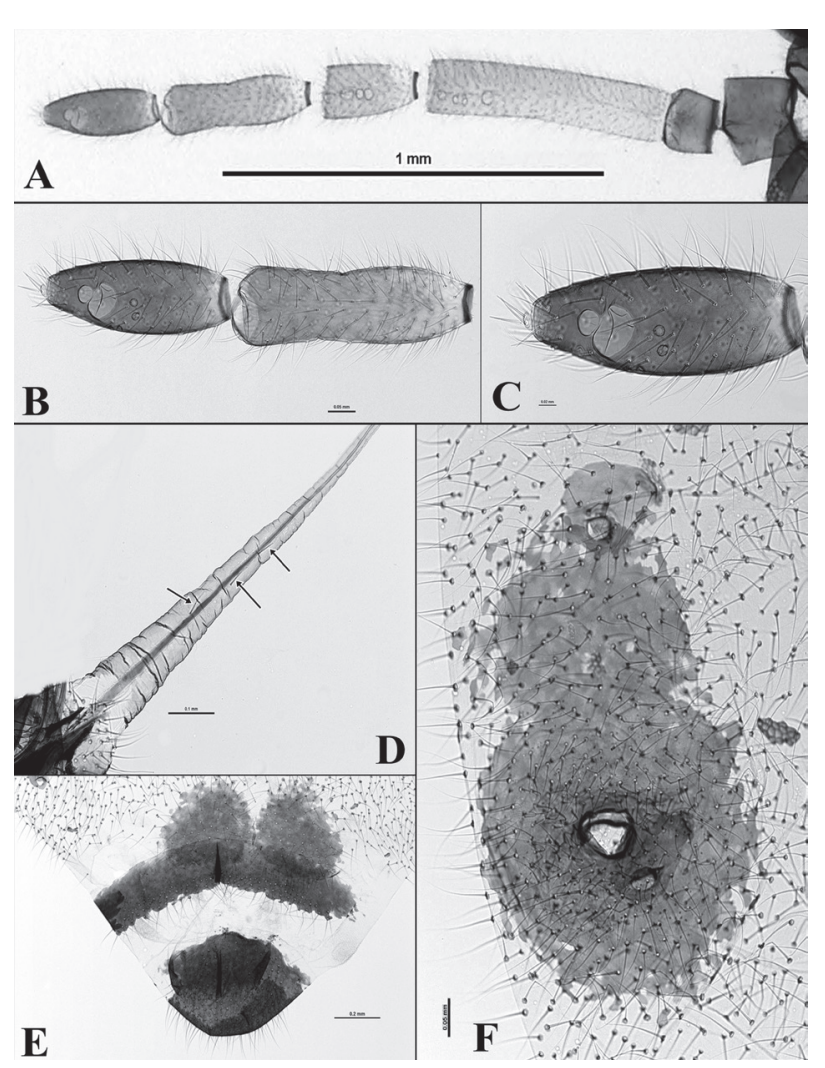

Figure 2. Stomaphis graffi - fundatrix: (a) antenna, (b) antennal segments V and VI, (c) antennal segment VI, (d) labrum (arrows indicate setae), (e) distal part of abdomen with subgenital plate and cauda, (f) siphuncular sclerite.

Table 1. Stomaphis longirostris $(\mathrm{n}=4)$ and Stomaphis graffii $(\mathrm{n}=5)$. Measurements of fundatrices (in $\mathrm{mm})$.

\begin{tabular}{|c|c|c|}
\hline Character & S. longirostris & S. graffii \\
\hline Body length & $6.27-6.55$ & $5.95-6.05$ \\
\hline Antennae length & $1.95-2.16$ & $1.89-2.05$ \\
\hline Ant. segm. III & $0.63-0.69$ & $0.63-0.72$ \\
\hline Ant. segm. IV & $0.28-0.31$ & $0.23-0.27$ \\
\hline Ant. segm. V & $0.36-0.46$ & $0.40-0.42$ \\
\hline Ant. segm VI & $0.28-0.31$ & $0.31-0.34$ \\
\hline Ant. VI terminal process & $0.04-0.06$ & $0.06-0.08$ \\
\hline Ant VI base & $0.23-0.26$ & $0.25-0.27$ \\
\hline Apical segment of rostrum & $0.64-0.68$ & $0.58-0.64$ \\
\hline Second segment of middle tarsus & $0.30-0.32$ & $0.30-0.31$ \\
\hline First segment of hind tarsus & $0.14-0.15$ & $0.13-0.15$ \\
\hline Second segment of hind tarsus & $0.38-0.41$ & $0.39-0.41$ \\
\hline SIPH slcerite length & $0.54-0.62$ & $0.65-0.80$ \\
\hline SIPH sclerite width & $0.30-0.39$ & $0.37-0.46$ \\
\hline Subgenital plate length & $0.54-0.62$ & $0.32-0.35$ \\
\hline Subgenital plate width & $0.69-0.75$ & $0.75-0.80$ \\
\hline Rhinaria on ant. segm. III & $0-7$ & $4-9$ \\
\hline Rhinaria on ant. segm. IV & $4-6$ & $3-5$ \\
\hline Rhinaria on ant. segm. V & $1-2$ & $1-2$ \\
\hline Rhinaria on ant. segm. VI & $3-6$ & $4-6$ \\
\hline Number of ommatidia & $17-23$ & $10-20$ \\
\hline
\end{tabular}




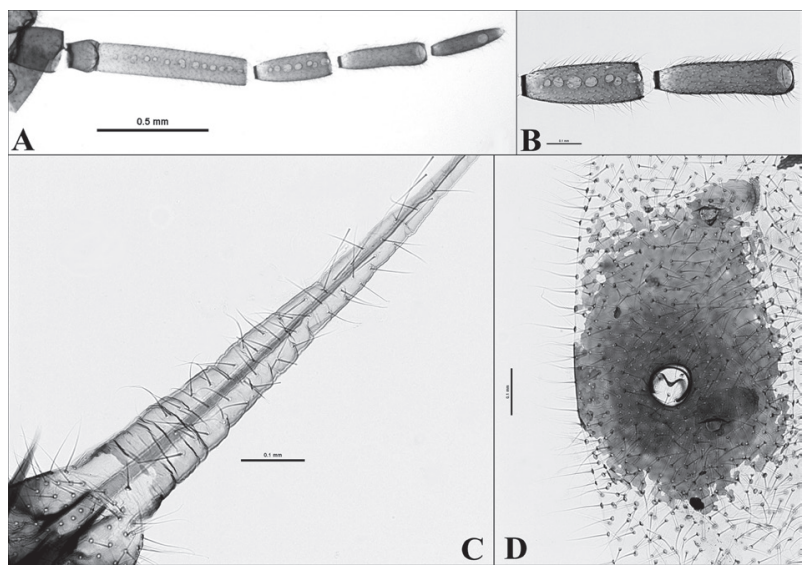

Figure 3. Stomaphis longirostris - apterous viviparous female: (a) antenna, (b) antennal segments III and IV, (c) labrum, (d) siphuncular sclerite.

diameter of tibia in the middle. HT II $1.30-1.36$ times MT II; ant. segm. IV/ HT II $0.51-0.67$;

Abdomen membranous, covered with fine, long setae, with three rows of dark, intersegmental insertions.
Spiracles on very small, pigmented scleroites. Siphuncular pores on distinct, sclerotised cones. Anterior part of the cone always extended and paler (Fig. 2f, unlike in apterous viviparous female - Fig. 4d). Weak, paired spinal sclerites, always broken into a few small scleroites, sometimes present on abdominal tergite VII. Abdominal tergite VIII distinctly and uniformly sclerotised, covered with a few rows of long setae in the posterior margin of the tergite. Subgenital plate separated into two big sclerites, covered with long setae. Cauda rounded, sclerotised, covered with many long setae (Fig. 2e).

Diagnosis: From the apterous viviparous female it may be distinguished by (fundatrix vs apterous viviparous female):

- higher ratio of ant. segm. III to ant. segm. IV: $2.44-$ 2.87 vs $1.55-2.46$

- lower ratio of ant. segm. IV to ant. segm. V: $0.56-$ 0.67 vs $0.76-1.16$

- lower ratio of ant. segm. IV to HT II: $0.52-0.67$ vs $0.69-0.92$

\section{Key to known fundatrices of European species of the genus Stomaphis}

1 Ventral plates present; spinal, paired sclerites present.

Ventral plates absent; spinal, paired sclerites present at most on VII abdominal segment, absent from other abdominal segments. S. wojciechowskii Depa

$\mathrm{R} I \mathrm{~V}+\mathrm{V} / \mathrm{HT} \|<2.0$, in life pale, dull, slightly wax powdered.... S. quercus (L.)

$\mathrm{R} I \mathrm{~V}+\mathrm{V} / \mathrm{HT} \|>2.0$, in life dark, shining

S. longirostris (F.)

$3 \mathrm{R}$ IV $+\mathrm{V} / \mathrm{HT}$ II $>1.64$, antIII/antIV $<2.43$, less than 5 setae on extended part of labrum...... S. graffii Cholod

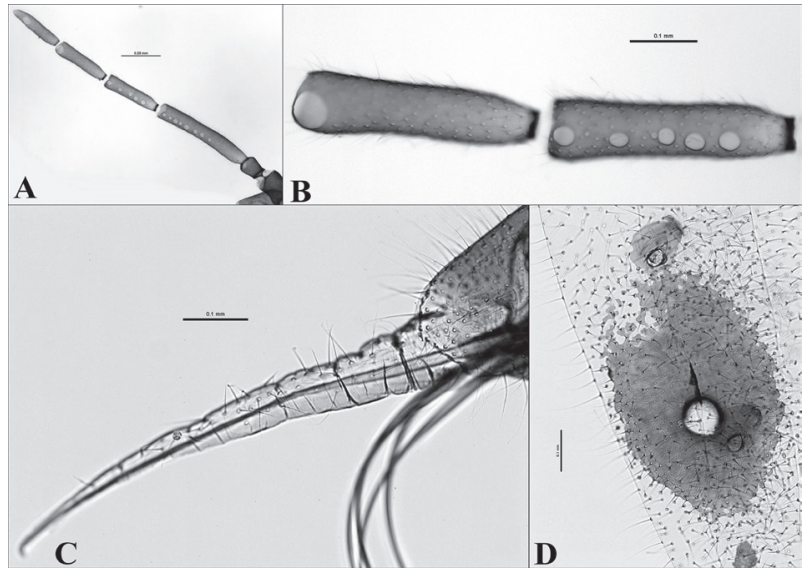

Figure 4. Stomaphis graffii - apterous viviparous female: (a) antenna, (b) antennal segments III and IV, (c) labrum, (d) siphuncular sclerite.

\section{Discussion}

The two morphs show some interesting features in their morphology, differentiating them from apterous viviparous morphs of both species.
The fundatrix of $S$. graffii is rather congruent in morphological features with its apterous viviparous morph, except for minor traits (as listed in the description), among which the more significant is the very short antennal segment IV (Fig. 2a and Fig. 4ab for comparison). The main characteristics of the species: HTII/MTII ratio and number of secondary rhinaria are within the range of variability typical for apterous viviparous females (Binazzi and Blackman 2003). Also the number of setae on labrum, although slightly smaller in fundatrices (614), matches the range of variability of apterous viviparous females (Fig. 4c) (3 - 26 according to Binazzi and Blackman (2003), 4 - 56 according to Depa and Mróz (2013)).

The most interesting morphological feature is the very low number of setae on the labrum of fundatrix of $S$. longirostris (Fig. 1d), which are hardly visible in the mounted specimens as they are prone to be broken off during mounting. Apterous viviparae of later generations (fundatrigeniae, virginogeniae and sexuparae) of this species have more than 20 , and often up to 40 setae on the labrum (Fig. 3c), distributed along its entire length (Binazzi and Blackman 2003). Lack of setae on labrum makes the fundatrix of this species similar to the apterous vivip- 


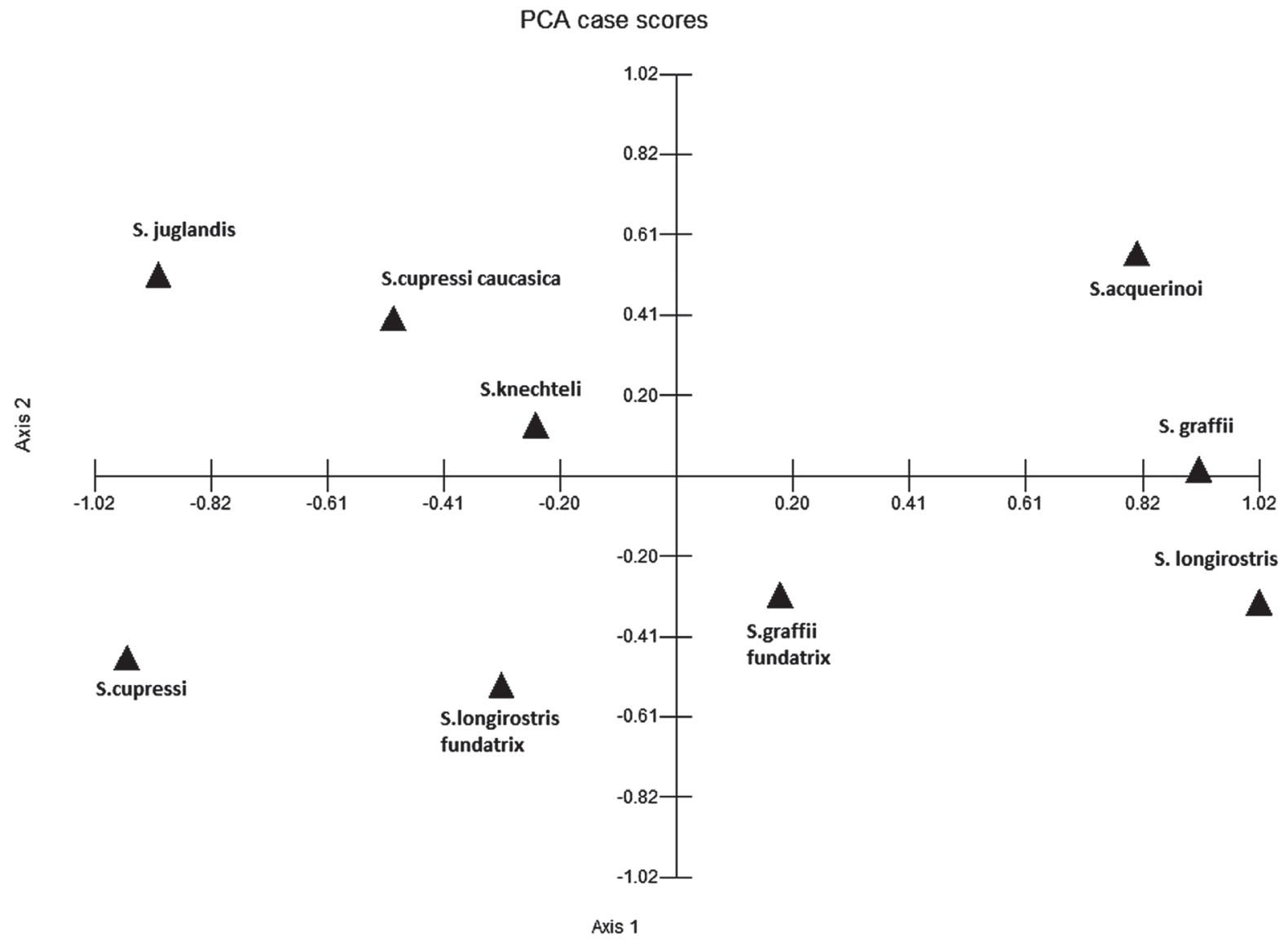

Figure 5. The results of PCA, showing similarity of the fundatrix of $S$. longirostris to $S$. cupressi.

arous female of $S$. cupressi Pintera - a species originally described from Cupressus in Kenya (Pintera 1965) but known also from the western Mediterranean region and Black Sea shores (Blackman and Eastop 1994; Akyürek et al. 2010). Fundatrices of $S$. longirostris also resemble apterous viviparous females of later generations of $S$. cupressi by having their HTII/MTII ratio less than 1.36, and could be mistakenly identified as that species (they also have as similar number of secondary rhinaria on antennal segments III and IV) if the host were unknown.

The PCA analysis confirmed the similarity of described fundatrices of $S$. longirostris to the S. cupressi (Fig. 5), with the most informative factors being the number of setae on labrum and the number of secondary rhinaria on antennal segment III. Species on the left side of the graph showed in Fig. 5 are species with a few setae on labrum while species on the right posses many setae on labrum. Similarly, species above the axis 2 in Fig. 5. have more rhinaria on antennal segment III while species below axis 2 have less rhinaria on this segment.

In the respect of analysed morphological traits, it seems that fundatrices of both studied species of Stomaphis show retrogressive features, which is concordant with the general view of aphid morphology, as reviewed by Miyazaki (1987). Among them, the most significant is the lack of setae on the elongated part of labrum of $S$. longirostris. If setae on the labrum play some role as receptors during feeding, it is interesting that S. longirostris exhibits such a radical loss of setae in its fundatrix, while the closely related species $S$. graffii does not. The phenomenon of weakening of sensory structures in the fundatrix during process of host specialization suggested by Shaposhnikov (1987) seems to be the explanation.

\section{Conclusion}

Fundatrices of both studied species showed some retrogressive morphological features, although did not show significant departure from general morphology of apterous viviparous females. $S$. longirostris showed larger reduction of setae on labrum than $S$. graffii, which is interesting in respect to phylogeny and host specificity of the genus.

\section{Acknowledgements}

Authors wish to thank Dr. Roger L. Blackman for his comments on the manuscript. We also thank the anonymous reviewer for helpful comments and suggestions. 


\section{References}

Akyürek B, Zeybekoğlu Ü, Görür G (2010) New records of aphid species (Hemiptera: Aphidoidea) for the Turkish fauna from Samsun province. Turkish Journal of Zoology 34: 421-424.

Binazzi A (2001) A new species of Stomaphis Walker from Italy, S. acquerinoi sp. n. (Aphididae Lachninae). Redia 84: 91-103.

Binazzi A, Blackman RL (2003) The Acer-feeding Stomaphis with description of a new species and new morphs (Hemiptera Aphididae Lachninae). Redia 86: 7-16.

Blackman RL, Eastop VF (1994) Aphids on the World's trees, An identification and information guide. CAB International \& The Natural History Museum, London. www.aphidsonworldsplants.info

Depa Ł, Mróz E (2012) Description of fundatrix morph of Stomaphis wojciechowskii Depa 2012 (Aphidoidea: Lachnidae). Genus 23(3): 425-428.

Depa , Mróz E (2013) Central European Acer - and Salicaceae-feeding Aphids of the Genus Stomaphis (Insecta: Aphidoidea: Lachnidae). Separate Species or Populations? Zoological Science 30(6): 509518. doi: 10.2108/zsj.30.509

Depa Ł, Mróz E, Szawaryn K (2012) Molecular identity of Stomaphis quercus (Hemiptera: Aphidoidea: Lachnidae) and description of a new species. European Journal of Entomology 109: 435-444. doi: 10.14411/eje.2012.056

Lorenz H, Scheurer S (1998) Biology and generation-order of Stomaphis quercus (Lachnidae) living on Betula pendula near Berlin, Ger- many. In: Nieto Nafria JM, Dixon AFG (Eds) Aphids in natural and managed ecosystems. Secretariado de publicaciones, Universidad de León, 243-250.

Mamontova WA (2012) Lachnid aphids (Homoptera: Aphidoidea: Lachnidae) from Eastern Europe and adjacent territories. Ukrainian Academy of Science, Naukova Dumka, Kiev, 390 pp. [in Ukrainian] Miyazaki M (1987) Forms and morphs of aphids. In: Harrewijn P, Minks AK (Eds) Aphids. Their biology, natural enemies and control. A. Elsevier, Amsterdam, 163-195.

Petrović O (1998) A new species of Stomaphis Walker (Aphididae) from Serbia. In: Nieto Nafria JM, Dixon AFG (Eds) Aphids in natural and managed ecosystems. Secretariado de publicaciones, Universidad de León, 423-429.

Pintera A (1965) Two new species of Lachnidae in the collections of the British Museum (Hemiptera, Aphidoidea). Entomologist 98: 60-63.

Qiao G, Zhang G (1999) A revision of Stomaphis Walker from China with descriptions of three new species (Homoptera, Lachnidae). Entomologia Sinica 6(4): 289-329.

Shaposhnikov GCh (1987) Evolution of aphids and relations to evolution of plants. In: Harrewijn P, Minks AK (Eds) Aphids. Their biology, natural enemies and control. A. Elsevier, Amsterdam, 409-414.

Takada H (2008) Life cycles of three Stomaphis species (Homoptera: Aphididae) observed in Kyoto, Japan: possible host alternation of $S$. japonica. Entomological Science 11: 341-348. doi: 10.1111/j.14798298.2008.00276.x 